\title{
ROBOT COMPANIONS: A TECHNOLOGICAL DREAM OR A HUMAN NIGHTMARE?
}

\author{
MARIA ISABEL ALDINHAS FERREIRA \\ Centro de Filosofia da Universidade de Lisboa. Faculdade de Letras da Universidade de Lisboa \\ University of Lisbon, Portugal \\ and \\ Instituto Superior Técnico/ Institute for Systems and Robotics \\ University of Lisbon. Lisbon, Portugal
}

isabelferreira@letras.ulisboa.pt

\section{Technological Dreams}

Star Wars is probably one of the most productive visual narratives in what relates the diversity of robot types. When thinking of this saga everyone recalls C-3PO, the golden droid, the size of an average man, lighted eyes, capable of comprehending over six million languages by organic life forms, machines, computer systems and other droids, but fundamentally capable of acting and interacting in a truly empathic, human-like way. According to the narrative, it was created from the discarded scrap and salvage of a 3PO unit droid, designed to interact with organics, and programmed primarily for etiquette and protocol, picked up in the Tatooine desert, by the nine-year-old-Anakin Skywalker and reassembled by him in order to build a droid that could help his mum.

The idea of having a robot at home capable of interacting, entertaining and helping with household chores has always corresponded to a technological dream shared by many, an already expected technological reality as a non gender specific online survey carried out recently, to a universe of about 100 adult respondents, showed.

However this expectation can hardly be satisfied just by the thousands of monofunctional robots, available in retail, like the iRobot Roomba, in spite of its promising statements, (depicted below) $)^{1}$, or by having at home a robot window or swimming pool cleaner.

${ }^{1}$ https://www.bestadvisers.co.uk/irobot-roomba-robot-vacuum? $\mathrm{s}=$ go\&gclid=CjwKCAjw98rpBRAuEiwALmoyv8oCPgUAOsF_EUZ4qfK8mcVJ2sif-3FibZ8RGtRp6XZDio72cL8TxoCrR0QAv 


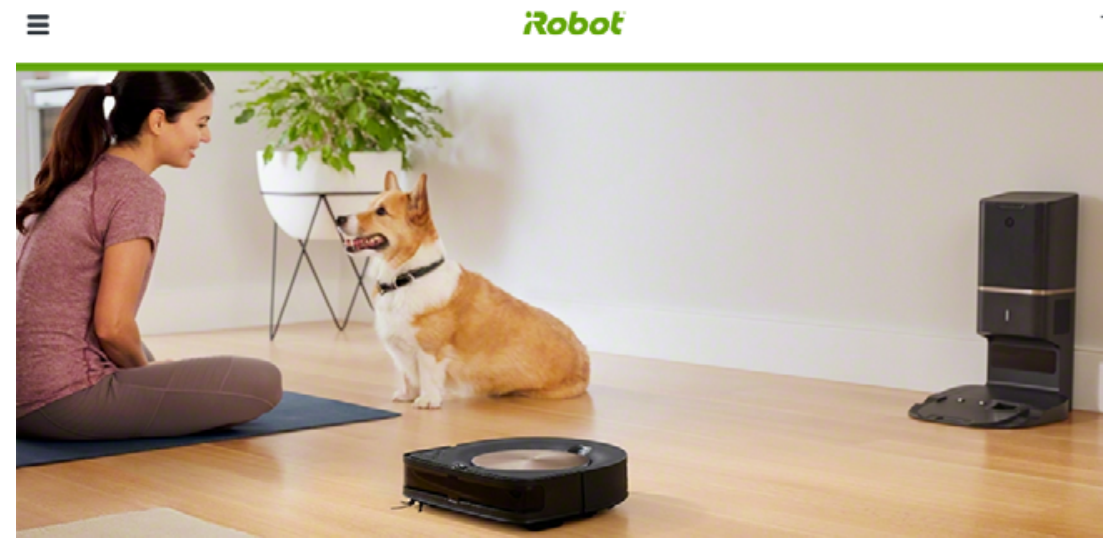

Figure 2: Mono-functional Robots

Best iRobot Roomba Robot Vacuums in the UK

Review \& Comparison, Last Update July 15, 2019

Don't want to waste your time on vacuuming carpeted floors? Get an iRobot Roomba Vacuum, an automatic helper that will do all the tedious work for you, requiring little to none of your time and effort. Read on our selection of the best iRobot models available and pick the one that suits you most ${ }^{2}$.

As the e-book Social Robots - by KPMG 2016 refers there is anecdotal evidence that globally society is becoming progressively more open to accepting robotic technology at home, namely robot companions.

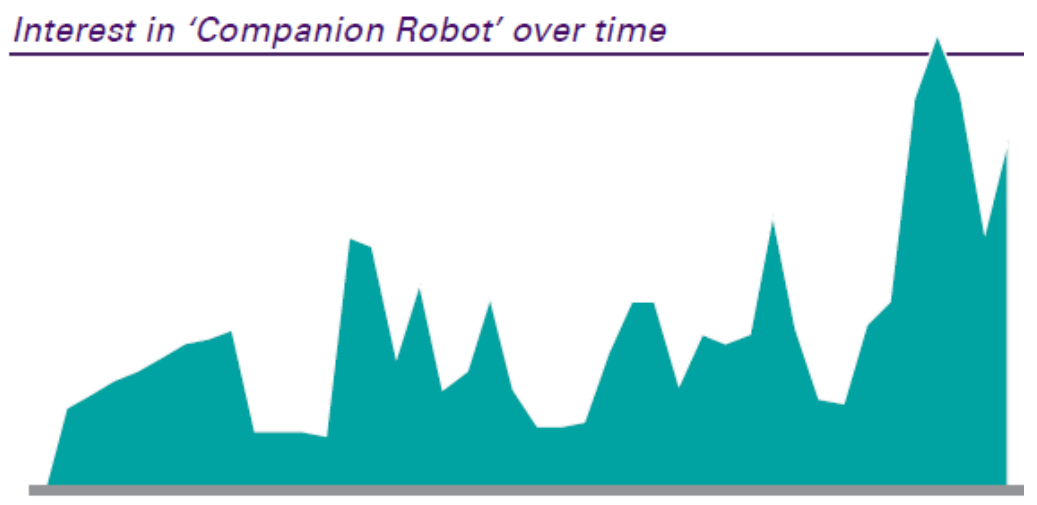

Oct- Dec- Feb- Apr- Jun- Aug- Oct- Dec- Feb- Apr- Jun- Aug- Oct- Dec- Feb- Apr- Jun- Aug- Oct- Dec- Feb$\begin{array}{lllllllllllllllllllll}12 & 12 & 13 & 13 & 13 & 13 & 13 & 13 & 14 & 14 & 14 & 14 & 14 & 14 & 15 & 15 & 15 & 15 & 15 & 15 & 16\end{array}$

Figure 3: Interest in Companion Robot between 2012 and 2016 in KPMG 2016

Fiction and dreaming are, in fact, on the verge of becoming a shared reality in developed countries where social robot prototypes, already being massively produced by robotic 
industry, are expected to shortly populate all domains of human existence. In Pepper the First Machine of its Kind: A Mass Produced Sociable Humanoid Robot, Pandey and Gélin (2018) refer that about 10,000 Peppers have already been sold, mainly in Japan. Some 3,000 of them are serving in various B2B applications: Pepper welcomes customers in SoftBank shops, sushi bars, clothing stores, and Nespresso boutiques and roughly 7,000 of the robots are in the domestic use, with consumers who want to experience life with a robot at home. In Europe, successful Pepper trials have been performed in French railway stations, at Carrefour supermarkets, at health-care and elder-care facilities, and on Costa Cruise ships. In the United States, Pepper can be found, for instance, in San Francisco's Westfield mall.

\section{Robot Companions: A Forthcoming Reality}

\subsection{Innovation and Market Growth}

Pandey and Gélin (2018) refer that considering end users and other stakeholders' feedback is fundamental for discovering R\&D challenges to be solved for the greater societal impact of Pepper- like social robots and their accompanying technology

But the development and update of all technology depends on investment and this is closely related to market growth. In fact, the main drivers for investment are:

(i) social demand based on real needs or just aspirations and/or the perspective of this possible increasing demand on the short term, strategic importance for local and/or global economy.

The growth of the first main driver will heavily depend on the adequate marketing campaigns targeting specific user groups. These marketing campaigns will focus on

- the innovative character of the product and the potentialities of this technology to enhance the quality of life and well-being of end-users, as well as its role fostering new life styles that tend to be perceived as fashionable.

- $\quad$ user satisfaction translated in 5 basic key factors- $5 \mathrm{SKF}$

$\checkmark$ Efficiency - it produces the desired effects in the scheduled time completely attaining the established goals.

$\checkmark$ Simplicity- not requiring complex protocols to be followed by the user- simple and very easy reading/operating interfaces

$\checkmark$ Safeness - that causes no harm either to users or to the environment

$\checkmark$ Reliability- that runs according to the established protocols

$\checkmark$ Trustworthiness- a technology on which the user can safely depend on

The concept of innovation always incorporates the features "newness and uniqueness" (Watchravesringkan, et al., 2010) and one can distinguish between evolutionary innovation also called incremental innovation and revolutionary, or radical innovation (Calantone, et al., 2010). These are in fact two distinct epiphenomena that characterize the evolutionary process inherent to all technological development along a virtual timeline. Radical innovation 
generally causes several forms of disruption with reflexes on the life styles and patterns of behavior, usually also demanding a market redefinition,: On the other hand incremental innovation comes naturally in an almost undetectable way and following some progression with minor and less risky changes. Usually after radical innovation a more or less long period of incremental innovation follows, establishing and consolidating not only the relationship of the consumer with the product but also the eventual new lifestyles.

One of the main segment of consumers presently targeted by marketers for domestic robots, namely robot companions, is that of the elderly population whose demands are expected to drive exponentially the expansion of the global personal robotics market.

\subsection{The Robot Companions Main Target Market}

According to the 2018 World Population Data Report ${ }^{3}$ the Population Age Structure, i.e. the distribution of individuals according to the categories (1) Children: 0-14; (2) Working Age:15-64 and (3) Seniors- +65 has been changing in the last decades.

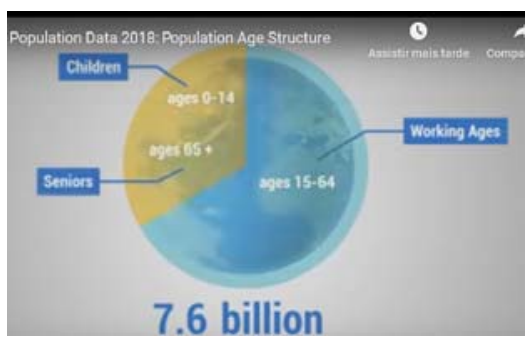

Figure 4: Distribution of individuals according to age related categories

As the report points out, countries experience changes in Population Age Structure at different times and rates, but whenever and wherever this phenomenon occurs significant social, economic and political changes take place. Europe has been crossing a period of Demographic Transition where the proportion of population aged 65 and older is expected to increase from $20 \%$ in 2018 to $30 \%$ in 2050, causing a redefinition of its Population Age Structure and posing specific challenges to societal organization in order to preserve the quality of life of senior citizens, while maintaining the sustainability of the overall economy, namely that of the welfare system and the stability and cohesion of the social tissue.
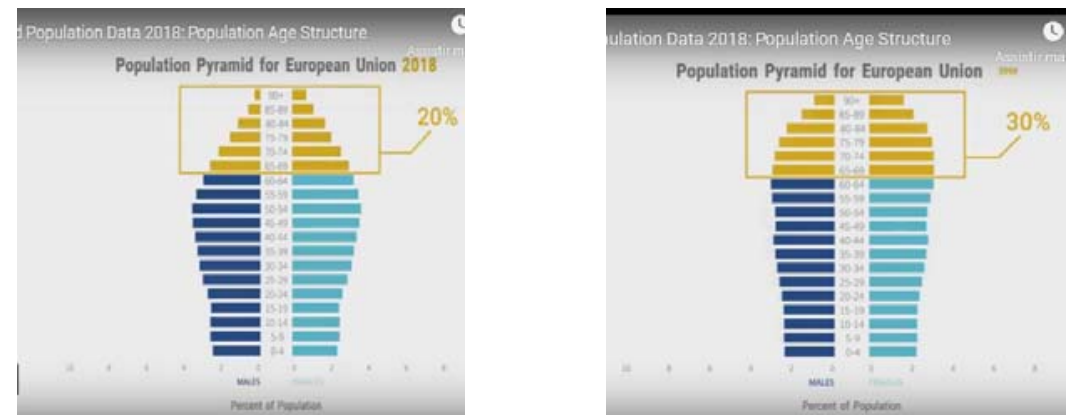

Figure 5: Population Pyramid in 2018 and 2050

${ }^{3}$ https://www.worldpopdata.org/ 
The economic changes that have been taking place for decades with the progressive alteration of the means of production, the unstable character of today's labour market, the demand for mobility and constant need of adaptation to new work environments, the precariat that haunts the workforce... introduced social and cultural modifications with profound reflexes on the way individuals interact, establish links, bonds and eventually love each others. One of the most damaging reflexes is the erosion of the affective intergenerational ties and interdependencies that traditionally guaranteed the care and bringing up of the very young by their elder and later the care and affective support of the elderly by their younger close ones.

Loneliness is an inherent negative feature of our society ${ }^{4}$, horizontal to all cohorts, an epidemic, as the New York Times has declared ${ }^{5}$. Causing severe damages to mental and physical health this problem has called the attention of politicians ${ }^{6}$ occupying presently the political agenda of political parties and governance and even calling for a specific Ministry, as in the case of the $\mathrm{UK}^{7}$ where recent statistics revealed that about 200,000 citizens tend to not communicate with friends or relatives even once per month, on average. ${ }^{8}$

This loneliness scenario gets substantially aggravated in the case of older cohorts that are no longer able to socially interact at work, whose descendants have probably long ago moved away from home, whose ancestors no longer exist, whose life has often just lost purpose and goal and that frequently experience chronic health conditions associated to decrease of mobility capacity and physical and/or psychological pain.

Age UK, which commissioned a survey on this topic, said the results highlighted a growing number of chronically lonely older people, as half a million people over the age of 60 usually spend each day alone, with no interaction with others, and nearly half a million more commonly do not see or speak to anyone for five or six days a week ${ }^{9}$.

On the devastating effects of loneliness, Carla M. Perissinotto, a geriatrician at the University of California, San Francisco, declared: ${ }^{10}$ "The profound effects of loneliness on health and independence are a critical public health problem, It is no longer medically or ethically acceptable to ignore older adults who feel lonely and marginalized."

From a marketing perspective, pushing senior care seems to be the next big thing. Robotic technology seems capable of encountering all the needs of this specific cohort. The pressure to find workable solutions have pointed to the potential assistance given by robot companions capable of enrolling in different forms of social interaction, capable of monitoring the user's physical conditions and advising on a series of related issues, capable of fostering communication with relatives via skype or other interface, capable of entertaining and amusing as a possible technological solution.

\footnotetext{
${ }^{4}$ Cf. The Swedish Theory of Love (2015)

${ }^{5} \mathrm{https}: / /$ www.nytimes.com/2016/09/06/health/lonliness-aging-health-effects.html

The study by Brigham Young University compared the health risks of loneliness and social isolation versus ohesitv and found that social isolation raised a nerson's risk of death hv 50 nercent. while ohesitv raised it bv iust 30 percent. https://rekordcenturion.co.za/137384/loneliness-deadlier-than-obesity/

${ }^{6} \mathrm{Cf}$ Catherine Fox

${ }^{7}$ Britain became the first European nation in mid-January to name a "minister of loneliness," amid studies revealing that roughly 10 percent of all Brits regularly feel isolated.

$8 \mathrm{https}: / /$ www.theguardian.com/world/2019/jun/17/half-of-britons-socialise-with-family-and-friends-at-most-once-amonth

${ }^{9} \mathrm{https} / / / \mathrm{www} \cdot$ theguardian.com/society/2017/jan/06/half-a-million-older-people-spend-every-day-alone-poll-shows

${ }^{10} \mathrm{https}: / /$ www.nytimes.com/2016/09/06/health/lonliness-aging-health-effects.html
} 


\section{Analysing Marketing Campaigns: The Case of ElliQ ${ }^{11}$}

The product we randomly chose is EliQ, produced by Intuition Robotics, a small social ronbot that sells via internet targeting the senior market.

ElliQ is introduced to the consumer through a series of stand points, a kind of producer manifesto and also videos in which users narrate their experience when interacting with the machine.:

Main stand points:

- The idea that I should learn how to use technology, that I need to figure out how to make it work for my life - this paradigm has become outdated.

- Older adults should not have to learn how to incorporate complex technologies into their lives. In fact, no one should!

- What if instead of learning how to use technology, the technology itself could show you all the ways it can be used?

- What if your devices could understand your needs, and refine itself to fit your personality, your environment, and your circumstance - in a way that is perfect for you?

- ElliQ learns - through the various interactions and questions - about

- your interests and desires around wellness, staying socially and staying socially and mentally active

- your day-to-day schedule and routines

- all the different ways that she can support your personal growth.

- If it's been a while since you've spoken to a family member, she may offer for you to make a video call, or send a sticker via text to let them know you are thinking of them.

- Or let's say you want to stay more cognitively fit, which can often be a challenge as we age ElliQ learns what your interests are (over time, and through your direct input) and begins to find the right content for you. If you like science, ElliQ can find interesting TED Talks to share or suggest to play trivia.

- Privacy - We have employed some of the best in the business to ensure the information your ElliQ learns about you stays your own. While ElliQ is sensing your environment in order to make better decisions in her efforts to help you, this data will never be sold, can never be hacked, and exists for the sole purpose of making your life better.

This kind of manifesto to the user, covers the 5 key satisfaction factors -SKP- we talked above:
$\checkmark$ Efficiency
$\checkmark$ Simplicity
$\checkmark$ Safeness
$\checkmark$ Reliability
$\checkmark$ Trustworthiness

${ }^{11} \mathrm{https}: /$ elliq.com/ 
As we referred the videos are complementary, emphasizing the degree of satisfaction towards the technology and how beneficial it has been

\section{Conclusions}

The development of robotic technology and AI, have forced us to look at our world, our reality from a detached point of view, a kind of look from outside, a bird's eye view, an observer's view if that was ever possible, given the inherent subjectivity of our view of the world.

Though pure objectivity is never possible, this necessary exercise has allowed us to realize the way we structure our reality, how we interact with our environment, how we make sense of it, how we interact with the Other and the fundamental role played by this Other in my own definition of Me as a human being in the definition of my own identity.

And from this bird's eye view we have the chance to realize that our world is far from perfect that our world models have to be reshaped, our priorities reestablished so that technology works for the benefit of the individual and of society In the particular case of robot companions, it involves realizing that living alone with a robot does not solve the problems inherent to loneliness, on the contrary it aggravates them, but that technology has the potential of promoting well-being in a world where humanness prevails.

\section{References}

Calantone, R. J., Harmancioglu, N. \& Droge, C., 2010. Inconclusive Innovation " Returns"': A Meta-Analysis of Research on Innovation in New Product Development. Journal of Product Innovation Management, pp. 2-13.

Ferreira, M-I.A. (2015) Robots in Ageing Societies: Ethical Challenges. In MIA Ferreira et al.eds A World with Robots (2016). Springer Verlag

Global Monotoring Report- 2015/2016. Demographic Change. World Bank http://pubdocs.worldbank.org/en/477081444102982630/Global-Monitoring-Report-2015Demographic-Change.pdf

Pandey, K., Gélin, R., Pepper the First Machine of its Kind: A Mass Produced Sociable Humanoid Robot. In IEEE ROBOTICS \& AUTOMATION MAGAZINE • september 2018

Rangaswamy, E., 2015. A Study on the Critical Success Factors of iPad Focusing on the Buyer Behaviour and Involvement. Amity Global Business Review, pp. 97-98.

Watchravesringkan, K., Hodges, N. N. \& Kim, Y.-H., 2010. Exploring Consumers' Adoption of Highly Technological Fashion Products: The Role of Extrinsi and Intrinsic Motivational Factors. Journal of Fashion Marketing and Management, p. 4. 
